\title{
THE AMMA RADIOSONDE PROGRAM AND ITS IMPLICATIONS FOR THE FUTURE OF ATMOSPHERIC MONITORING OVER AFRICA
}

by Douglas J. Parker, Andreas Fink, Serge Janicot, Jean-Blaise Ngamini, Michael Douglas, Ernest Afiesimama, Anna Agusti-Panareda, Anton Beljaars, Francis Dide, Arona Diedhiou, Thierry Lebel, Jan Polcher, Jean-Luc Redelsperger, Chris Thorncroft, and George Ato Wilson

\section{In the face of long-term decline, the AMMA research program has reactivated the} radiosonde network over West Africa. The lessons learned in AMMA have significance for the upper-air network throughout the continent.

$\mathrm{n}$ recent years the meteorological observing system in Africa has been in a worse state than that of any other populated continent. The declining observational network and the ongoing communication problems of West Africa are two of the major challenges for the monitoring and prediction of weather and climate, and for the establishment of early warning systems in the region. These realities motivated the $\mathrm{AMMA}^{1}$ (Redelsperger et al. 2006) and placed a high priority on improving the upper-air stations as part of AMMA's multiyear field experiment.

Since 2004, AMMA scientists have been working with operational agencies in Africa to reactivate silent radiosonde stations, to renovate unreliable stations, and to install new stations in regions of particular climatic importance. At the time of writing, 21 stations are active over West Africa (see Fig. 1 and

\footnotetext{
${ }^{1}$ All acronyms are explained in Table 1.
}

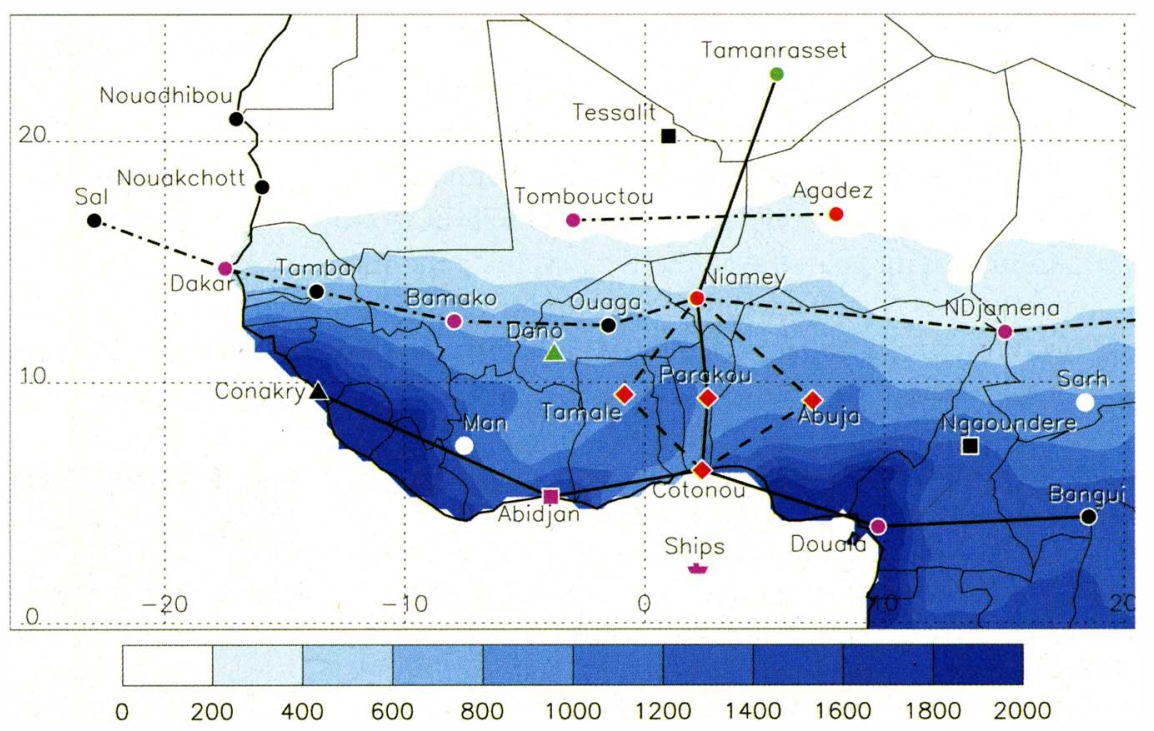

FIG. I. Key stations of the AMMA radiosonde network. "Tamba" is Tambacounda and "Ouaga" is Ouagadougou. Shapes denote the status: circles represent established stations, diamonds the new AMMA stations, squares are reactivated stations (or those reconnected to the GTS), and triangles are stations that operated temporarily in 2006 (Praia is not shown, as it is very close to Sal). Color indicates the planned operational frequencies in 2006: white indicates operational (I per day) with no GTS communications, black indicates I per day, magenta 2 per day, green 4 per day (Tamanrasset) or variable (Dano), and red achieved 4 per day during SOPs I-3, with 8 per day during IOPs. Refer to Table 2 for more details. The observed mean annual precipitation amount for the period $196 \mathrm{I}-90$ is contoured (up to 2,000 $\mathrm{mm} \mathrm{yr}^{-1}$ ), based on the VASClimo dataset (Beck et al. 2005). The "monsoon" transects are denoted by solid lines, the "zonal" and northern transects are dash-dotted, and the "southern quadrilateral" is dashed. 
CASE I: ABIDJAN-AN EXTREME EXAMPLE OF A STATION RENDERED
INACTIVE BY TECHNICAL PROBLEMS

The Abidjan station is a member of the GUAN and has had a long, reliable record of data collection. In June 2001 , the station was destroyed by a hydrogen explosion, which killed one of the observers. Abidjan, on the Guinea coast, lies in a critical location for monitoring the monsoon inflow to the West African region. Almost $5 \mathrm{yr}$ of climatic data were lost until the reactivation of the station in 2006; this from a region in which interannual variations in climate are critical to the livelihoods of the local population.

Despite funds being made available for a new ground station and consumables, through NOAA's support for GCOS, the reactivation of the station was held up for nearly 4 years because of the lack of replacement buildings. This very extreme and tragic example illustrates how radiosonde operations can be debilitated by the difficulty in performing repairs or maintenance at existing stations. At other sites, far smaller technical faults, for instance the loss of a cable connector costing a few dollars, can lead to a station being silent for many weeks or months.

Table 2), and during the period June to September 2006 some 7,000 soundings were made, representing the greatest density of radiosondes ever launched in the region, greater even than during GATE in 1974. An important goal of AMMA is to evaluate the impact of these data on weather and climate prediction for West Africa and for the hurricane genesis regions of the tropical Atlantic. A number of new atmospheric

AFFILIATIONS: PARKER - University of Leeds, Leeds, United Kingdom; FINK - University of Cologne, Cologne, Germany; JANICOT-LOCEAN, IRD, Paris, France; NGAMINI-ASECNA, Dakar, Senegal; DougLAS-National Severe Storms Laboratory/ NOAA, Norman, Oklahoma; Afiesimama-NIMET, Abuja, Nigeria; Agusti-Panareda ANd BelJAars-ECMWF, Reading, United Kingdom; DIDE-DMN, Cotonou, Benin; DIEDHIOU AND LEBEL-LTHE, IRD, Grenoble, France; POLCHER-IPSL, CNRS, Paris, France; RedelsPerger-CNRM, CNRS, Toulouse, France; THORNCROFT-SUNY at Albany, Albany, New York; WILSONGMet, Accra, Ghana

CORRESPONDING AUTHOR: Doug Parker, University of Leeds, Leeds LS2 9JT, United Kingdom

E-mail: doug@env.leeds.ac.uk

The abstract for this article can be found in this issue, following the table of contents.

DOI:10.1175/2008BAMS2436.I

In final form I February 2008

C2008 American Meteorological Society profiling systems are being used in West Africa, including UHF wind profilers, AMDARs, and satellite products. However, for operational purposes, for an intensive observational program, and for long-term climate monitoring there is currently no alternative to the radiosonde to provide comprehensive vertical profiles of winds and thermodynamics in the troposphere.

At the outset of planning for AMMA, we were conscious of the problems facing the upper-air network in Africa. Following GATE, Kuettner and Parker (1976) made some telling points about the observational network over the region, stating that "a number of planned World Weather Watch stations did not operate, although their priorities had been established more than 3 years before GATE," and that "real-time data acquisition ... was on average only $36 \%$ of that planned."

More recently, considerable effort has been devoted to establishing priorities for the radiosondes in the region, notably through GUAN. However, difficulties persist:

There remains a significant problem with the availability of data from up to one third of both the GUAN and full radiosonde network, especially in the tropics. These problems are occurring either because observations are not being taken due to lack of resources, or because data are not being exchanged

(GCOS 2003a), and more specifically there are problems of "inadequately trained staff, lack of equipment

\section{CASE 2: NGAOUNDERE-AN OPERATIONAL STATION WITH NO COMMUNICATIONS}

Ngaoundere (Cameroon) is one example of an operaNional station that has been silent to the outside world for many years. This station is in an excellent position for monitoring the monsoon inflow to central and eastern North Africa, as well as monitoring the upstream conditions for the many MCSs, which develop over the Jos Plateau in Nigeria. Although its activity has been a little intermittent, the station has made many soundings since 2000 , almost none of which have been reaching the GTS. The cost of a month's daily soundings, in consumables alone, amounts to some $\$ 8,000$, and apart from the use of the data by the local forecasters, these data were simply being wasted. AMMA has implemented a solution to the communication problems at Ngaoundere through a satellite $\mathrm{DCP}$, but the communications remain vulnerable. 
and consumables, equipment obsolescence, inoperative circuits and other telecommunications problems, shortage of funds, and social turmoil" (GCOS 2003b). Basing our vision of the existing stations in the region on messages received through the GTS, we embarked on the AMMA radiosonde program early in 2004 with a pessimistic opinion of existing capacity (Fig. 2). Many sites listed in the WMO database of upper-air stations (WMO 2006) had not reported data for many years, and very little information was available on the status of these stations; even those in the GCOS network.

Subsequent work has revealed that a number of stations, which appeared to be inactive, have in fact been operating but unable to transmit their data, or have simply suffered medium-term failure due to minor technical faults or failures in the supply of consumables. The two sidebars ("Case 1: Abidjan-An extreme example of a station rendered inactive by technical problems" and "Case 2: Ngaoundere-An operational station with no communications") provide typical examples of such problems, which were facing AMMA at the outset. In many ways, these cases may be seen as paradigms of the difficulties facing radiosonde stations in subSaharan Africa, and possibly in much of the developing world.

AMMA also encompassed a short, intensive
TABLE I. List of acronyms used in the text.

\begin{tabular}{|c|c|}
\hline AMDAR & Aircraft Meteorological Data Relay \\
\hline AMMA & African Monsoon Multidisciplinary Analysis \\
\hline ASECNA & $\begin{array}{l}\text { Agence pour la Sécurité de la Navigation Aérienne en Afrique et à } \\
\text { Madagascar }\end{array}$ \\
\hline DCP & Data collection platform \\
\hline DMN & Direction de la Météorologie Nationale \\
\hline EAMAC & L'Ecole Africaine de la Météorologie et de l'Aviation Civile \\
\hline ECMWF & European Centre for Medium-Range Weather Forecasts \\
\hline EOP & AMMA extended observing period, 2005-07 \\
\hline GARP & Global Atmospheric Research Project \\
\hline GATE & GARP Atlantic Tropical Experiment \\
\hline GCOS & Global Climate Observing System \\
\hline GMet & Ghana Meteorological Agency \\
\hline GPS & Global positioning system \\
\hline GTS & Global Telecommunication System \\
\hline GUAN & GCOS Upper Air Network \\
\hline IFA & Intensive Flux Array \\
\hline IHOP & International $\mathrm{H}_{2} \mathrm{O}$ Project \\
\hline IOP & Intensive observing period \\
\hline MCS & Mesoscale convective system \\
\hline MTN & Main Telecommunication Network \\
\hline NAME & North American Monsoon Experiment \\
\hline NASA & National Aeronautics and Space Administration \\
\hline NCEP & National Centers for Environmental Prediction \\
\hline NIMET & Nigerian Meteorological Agency \\
\hline NMS & National Meteorological Service \\
\hline NOAA & National Oceanic and Atmospheric Administration \\
\hline NWP & Numerical weather prediction \\
\hline ONM & Office National de la Météorologie \\
\hline OSE & Observing system experiment \\
\hline RTH & Regional telecommunications hub \\
\hline SALLJEX & South American Low-Level Jet Experiment \\
\hline SOP & AMMA special observing period \\
\hline TEMP & $\begin{array}{l}\text { Upper-level pressure, temperature, humidity and wind report from a } \\
\text { fixed land station (WMO code name) }\end{array}$ \\
\hline THORPEX & The Observing System Research and Predictability Experiment \\
\hline TOGA COARE & $\begin{array}{l}\text { Tropical Ocean Global Atmosphere Coupled Ocean-Atmosphere } \\
\text { Response Experiment }\end{array}$ \\
\hline TTI & AMMA task team I \\
\hline UHF & Ultra-high frequency \\
\hline VASClimO & Variability Analysis of Surface Climate Observations \\
\hline VCP & Voluntary Cooperation Programme \\
\hline VSAT & Very small aperture satellite terminal \\
\hline WG5 & AMMA working group 5 \\
\hline WMO & World Meteorological Organization \\
\hline
\end{tabular}


TABLE 2. The 24 operational radiosonde stations in the AMMA region. "MODEM" refers to the MODEM SR2K2 ground station, while DII and DIII are the Vaisala Digicora II and III, respectively. Success rates are based on real-time data reception at the ECMWF and therefore very much underestimate the number of soundings completed and archived for reanalysis. Conakry is not currently operational, while Man and Sarh have no reliable connection to the GTS.

\begin{tabular}{|c|c|c|c|c|c|c|c|c|c|c|c|}
\hline $\begin{array}{c}\text { WMO } \\
\text { station } \\
\text { No. }\end{array}$ & Station name & Lat & Lon & Ũ & 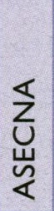 & 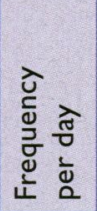 & 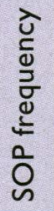 & $\begin{array}{l}\widehat{\partial} \\
\frac{0}{0} \\
\frac{\partial}{0} \\
\text { d } \\
\frac{2}{2} \\
0 \\
\underline{0}\end{array}$ & $\begin{array}{l}\text { Upgraded } \\
\text { ground } \\
\text { station }\end{array}$ & $\begin{array}{c}2006 \\
\text { success } \\
\text { rate }(\%)\end{array}$ & $\begin{array}{c}\text { Best } 2006 \\
\text { monthly } \\
\text { success } \\
(\%)\end{array}$ \\
\hline 65578 & ABIDJAN & $05^{\circ} 15^{\prime} \mathrm{N}$ & $03^{\circ} 56^{\prime} \mathrm{W}$ & $x$ & $x$ & 1 & 1 & 1 & DII (RS92) & 11 & 42 \\
\hline 65125 & ABUJA & $09^{\circ} 15^{\prime} \mathrm{N}$ & $07^{\circ} 00^{\prime} \mathrm{E}$ & & & 1 & 4 & 8 & DIII (new) & 23 & 97 \\
\hline 61024 & AGADEZ & $16^{\circ} 58^{\prime} \mathrm{N}$ & $07^{\circ} 59^{\prime} \mathrm{E}$ & & $x$ & 1 & 4 & 8 & DII (RS92) & 70 & 100 \\
\hline 61291 & BAMAKO & $12^{\circ} 32^{\prime} \mathrm{N}$ & $07^{\circ} 57^{\prime} \mathrm{W}$ & & $x$ & 2 & 2 & 2 & DII (RS92) & 81 & 97 \\
\hline 64650 & BANGUI & $04^{\circ} 24^{\prime} \mathrm{N}$ & $18^{\circ} 31^{\prime} \mathrm{E}$ & & $x$ & 1 & 1 & 1 & MODEM & 11 & 39 \\
\hline 65344 & COTONOU & $06^{\circ} 21^{\prime} \mathrm{N}$ & $02^{\circ} 23^{\prime} \mathrm{E}$ & & $x$ & 1 & 4 & 8 & MODEM new & 57 & 97 \\
\hline 61641 & DAKAR/YOFF & $14^{\circ} 44^{\prime} \mathrm{N}$ & $17^{\circ} 30^{\prime} \mathrm{W}$ & $x$ & $x$ & 2 & 2 & 2 & DII (RS92) & 89 & 100 \\
\hline 64910 & DOUALA & $04^{\circ} 0 I^{\prime} N$ & $09^{\circ} 42^{\prime} \mathrm{E}$ & $x$ & $x$ & 2 & 2 & 2 & DII (RS92) & 76 & 95 \\
\hline 64700 & NDJAMENA & $12^{\circ} 08^{\prime} \mathrm{N}$ & $15^{\circ} 02^{\prime} \mathrm{E}$ & & $x$ & 1 & 2 & 2 & DII (RS92) & 72 & 98 \\
\hline 64870 & NGAOUNDERE & $07^{\circ} 2 I^{\prime} N$ & $13^{\circ} 34^{\prime} \mathrm{E}$ & & $x$ & 1 & 1 & 1 & DII (RS92) & 61 & 100 \\
\hline 61052 & NIAMEY & $13^{\circ} 29^{\prime} \mathrm{N}$ & $02^{\circ} 10^{\prime} \mathrm{E}$ & $x$ & $x$ & 2 & 4 & 8 & DII (RS92) & 72 & 99 \\
\hline 61415 & NOUADHIBOU & $20^{\circ} 56^{\prime} \mathrm{N}$ & $17^{\circ} 02^{\prime} \mathrm{W}$ & & $x$ & 1 & 1 & 1 & DII (RS92) & 25 & 90 \\
\hline 61442 & NOUAKCHOTT & $18^{\circ} 06^{\prime} \mathrm{N}$ & $15^{\circ} 57^{\prime} \mathrm{W}$ & & $x$ & 1 & 1 & 1 & DII (RS92) & 61 & 97 \\
\hline 65503 & OUAGADOUGOU & $12^{\circ} 21^{\prime} \mathrm{N}$ & $01^{\circ} 31^{\prime} \mathrm{W}$ & & $x$ & 1 & 1 & 1 & MODEM & 48 & 100 \\
\hline 65330 & PARAKOU & $09^{\circ} 21^{\prime} \mathrm{N}$ & $02^{\circ} 37^{\prime} \mathrm{E}$ & & & 1 & 4 & 8 & MODEM new & 36 & 82 \\
\hline 08594 & $S A L$ & $16^{\circ} 44^{\prime} \mathrm{N}$ & $22^{\circ} 57^{\prime} \mathrm{W}$ & $x$ & & 1 & 1 & 1 & & 96 & 100 \\
\hline 65418 & TAMALE & $09^{\circ} 30^{\prime} \mathrm{N}$ & $00^{\circ} 5 I^{\prime} \mathrm{W}$ & & & 1 & 4 & 8 & DIII (new) & 17 & 58 \\
\hline 60680 & TAMANRASSET & $22^{\circ} 48^{\prime} \mathrm{N}$ & $05^{\circ} 26^{\prime} \mathrm{E}$ & $x$ & & 1 & 4 & 4 & & 98 & 100 \\
\hline 61687 & TAMBACOUNDA & $13^{\circ} 46^{\prime} \mathrm{N}$ & $13^{\circ} 4 I^{\prime} \mathrm{W}$ & $x$ & & 1 & 1 & 1 & MODEM & 52 & 100 \\
\hline 61202 & TESSALIT & $20^{\circ} 12^{\prime} \mathrm{N}$ & $00^{\circ} 59^{\prime} \mathrm{E}$ & & $x$ & 1 & 1 & 1 & DII (RS92) & 0 & 0 \\
\hline 61223 & TOMBOUCTOU & $16^{\circ} 43^{\prime} \mathrm{N}$ & $03^{\circ} 00^{\prime} \mathrm{W}$ & & $x$ & 1 & 1 & 1 & DII (RS92) & 2 & 10 \\
\hline 61831 & CONAKRY & $09^{\circ} 34^{\prime} \mathrm{N}$ & $13^{\circ} 37^{\prime} \mathrm{W}$ & & & & & & No upgrade & & \\
\hline 65548 & MAN & $7^{\circ} 23^{\prime} \mathrm{N}$ & $7^{\circ} 3 I^{\prime} \mathrm{W}$ & & $x$ & & & & DII (RS92) & & \\
\hline 64750 & SARH & $09^{\circ} 09^{\prime} \mathrm{N}$ & $18^{\circ} 23^{\prime} \mathrm{E}$ & & $x$ & & & & DII (RS92) & & \\
\hline
\end{tabular}

campaign involving a network of pilot balloon (pibal) stations $^{2}$ in the western part of the region: Senegal, Guinea, Mali, and Mauritania. This activity both exposed the dilapidated state of the operational pibal network in the region and demonstrated that important upper-air data can be collected at relatively low cost through pibal soundings. More information on the AMMA pibal program is given in "The 'lost' pibal networks of Africa" sidebar.

\footnotetext{
${ }^{2}$ A pilot sounding involves a passive balloon, which is tracked from the ground to obtain a profile of winds as a function of
} height.
AMMA OBJECTIVES IN RELATION TO INTERNATIONAL AND REGIONAL STRATEGY. AMMA has been an atypical scientific program, in having a set of long-term objectives related to enhancing the operational monitoring network for the region, beyond the lifetime of its field experiment. The long-term perspective involves direct investment in the existing network and thorough scientific evaluation of the optimal network for the future.

Out of a network of 24 radiosonde stations in the region, only two, at Dano (Burkina Faso) and Praia (Cape Verde), were installed for AMMA on a temporary basis in 2006. Although soundings were carried 
In the past, many parts of Africa have loperated effective pibal networks. These observations are inexpensive (see Table 3), and where observers are well trained and where skies are less cloudy, the observations can provide very high quality wind profile information.

For pibal soundings, the ground instrumentation comprises an optical meteorological theodolite, with which to track the balloon, and a computer (or a pocket calculator) on which to process, and possibly transmit, the data. A 40-g balloon is typically launched and under good conditions (low winds and high visibility) pibals can be tracked to over $10-\mathrm{km}$ altitude (around $250 \mathrm{hPa}$ ). At night, pibals are tracked by suspending a small candle below the balloon, in a paper "concertina," which is typically visible for around $10 \mathrm{~min}$ of ascent (around 2,000 m).

Although many countries in West Africa still operate pibal stations, their state of disrepair is impressive. During SOP3, a U.S. team traveled to Senegal, Mauritania, Mali, and Guinea seeking to upgrade the pibal network for the
August-September 2006 NASA-AMMA activities. Nine pibal sites were visited; only two had been making any observations during the previous month. Surprisingly, the most serious deficiency was the theodolite condition: most lacked a working high-magnification lens. This prevents tracking balloons for more than about $10 \mathrm{~min}$ (around 2,000 m) and contributes to the notion that the observations have limited value. The lack of gas, or the components required to generate the hydrogen, was another common problem. At one station, the lack of a specialized broom (which we estimated could not have cost more than $\$ 50)$ prevented the station's staff from cleaning the cylinder's interior, and from making observations for the previous $3 \mathrm{yr}$. Much of the problem lies with the supervision of the stations. In ASECNA countries most pibal stations are under the authority of the NMS, whose financial resources are generally low.

The soundings made in AMMA SOP 3 were used to analyze hurricane precursor vortices passing from West Africa over the tropical Atlantic. However, data assimilation statistics from the ECMWF have revealed that pibals from the operational stations in this region have very large variations in the bias and standard deviation of departures from the short-range model forecast (AMMA-EU 2006). This indicates that the pibal data are very noisy and as a result, the majority of pibals are in the "blacklist" and are not assimilated.

Many people would like to see the pibal network revitalized in West Africa: the pibals are attractive in being realistically within the budgets of local meteorological services, and there could be potential for a network with excellent spatial and temporal coverage. There have been some recent examples of successful pibal networks being operated, albeit in a research configuration (SALLJEX, Vera et al. 2006; NAME, Higgins et al. 2006). However, the current situation is a bleak one, with many pibal stations inoperable and few of the data being used, in Africa or elsewhere. Any recovery of this network will need to address many scientific as well as logistical problems.
FIG. 2. Data reception through the GTS from West African stations in 2003. Each station is identified with a disk, the upper half of which refers to 0000 UTC (night) soundings and the lower half to I 200 UTC (day). The fractional shading of each semicircle denotes the fraction of data received. An east-west transect through the Sahel from Sal to Agadez is reasonably well observed, but there are no data from the monsoon inflow zone between Dakar and Douala and few data at night. Note that the very reliable station of Tamanrasset is not included in this analysis. ASECNA countries are shaded yellow. For station names consult Fig. I.

out at Conakry during August and September 2006, financial resources did not permit longer-term investment at this particular site. Apart from these temporary activities, all other expenditure on the network has been in existing or new operational stations,

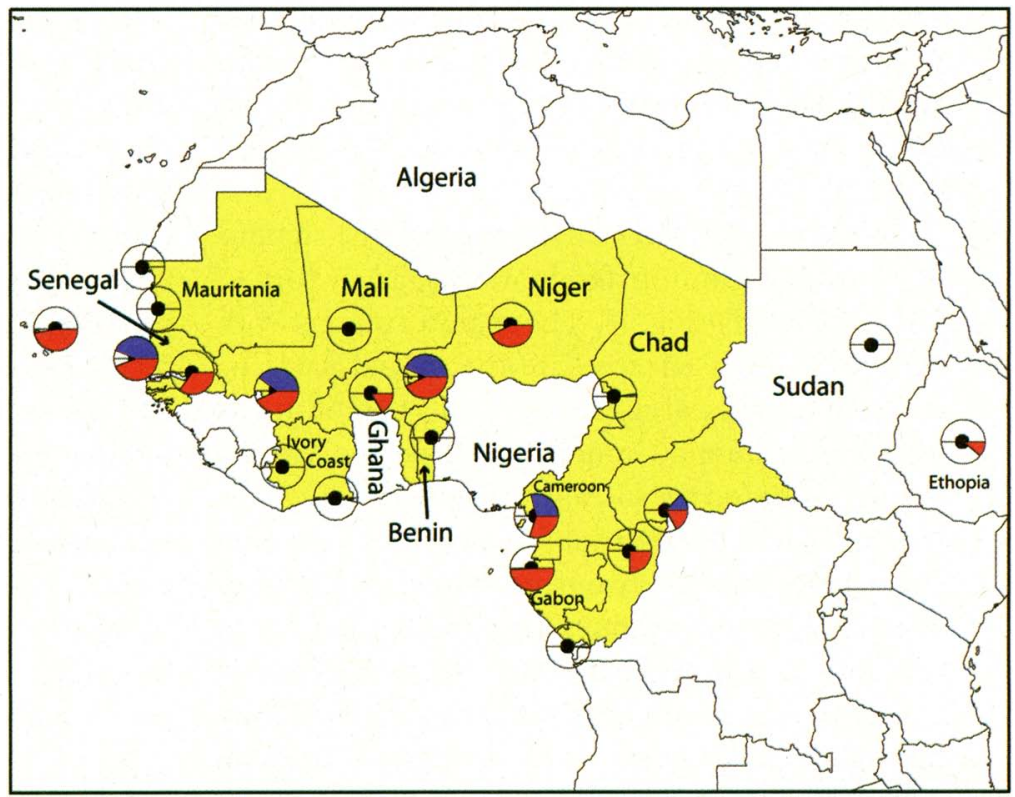

which have, in principle, a longer-term future. The remaining 21 stations are listed in Table 2, and of these, four are new stations, all in the Guinea coast 


\begin{tabular}{|c|c|c|}
\hline Item & Detail & $\begin{array}{c}\text { Approximate cost } \\
\text { (U.S. dollars) }\end{array}$ \\
\hline \multirow[t]{2}{*}{ Ground station } & New & $50,000-120,000$ \\
\hline & Refurbished/upgraded & $7,000-17,000$ \\
\hline Buildings & Basic balloon shed & 14,000 \\
\hline Gas cylinder & Each (two needed) & 8,000 \\
\hline Electrolytic gas generator & & 50,000 \\
\hline Theodolite & Used/new & $800-8,000$ \\
\hline Sonde + balloon + gas & $350-g$ balloon & $200-280$ \\
\hline Pilot balloon $($ pibal) + gas & 40 -g balloon & 10 \\
\hline
\end{tabular}

part of the observational strategy. The SOP radiosoundings were performed on a "quadrilateral" (akin in both configuration and function to the IFAs of TOGA COARE or IHOP), from which, in principle, advective fluxes can be computed to estimate budgets of energy, water, and momentum (e.g., Johnson and Ciesielski 2000; Carr and Bretherton 2001).

\section{OPERATIONAL ASPECTS OF RADIOSOUNDINGS AND PIBAL SOUNDINGS IN WEST AFRICA. The basic}

zone, where there has been a conspicuous absence of upper-air data for many years.

To balance the different scientific and operational objectives of the AMMA radiosonde program, a management group was established-termed "TT1"-bringing together research scientists, operational agencies in Africa making the soundings, and operational centers in Europe and the United States whose models assimilate the data. The largest organization managing operational soundings in West Africa is ASECNA, a multinational agency operating in 17 countries. Working with ASECNA has provided a single management point for 12 AMMA-involved African nations; however, each of these nations also has its own NMS, whose relationship with ASECNA is often complex. AMMA also works closely with NIMET, GMet, the DMN of Guinea, and the Algerian ONM. Among its members, TT1 includes two members of the GUAN program.

To achieve AMMA's different goals, the stations were grouped into different arrays, according to scientific needs (Fig. 1). The monitoring network was designed to encapsulate the spatial patterns controlling the local climate-notably the constrasts between the humid Guinea coast zone and the dry Saharan zone (on the so-called climate transect) - as well as the temporal variability, with the monsoon circulation exhibiting an intense diurnal cycle (Parker et al. 2005) requiring multiple soundings per day to capture it. During the EOP (2005-07), we have aimed to quantify the atmospheric system and its variability throughout at least two monsoon seasons. In 2006, AMMA also conducted intensive analysis of the atmosphere in SOPs, when research aircraft, ships, radar, and other facilities made observations at high resolution. Frequent radiosoundings (up to eight daily) at mesoscale spatial separation were an integral ingredients of a radiosounding are the sonde, the balloon, gas for the balloon, and a ground station to receive the sonde's signal and process the message. However, in practice many more considerations must be taken into account, including the training of staff, the availability of buildings and utilities, communications with the outside world, and the management of the whole operation.

In 2002, all of the operational radiosonde stations marked on Fig. 1, with the exception of Sal, were launching the Vaisala RS80 GPS radiosonde. The RS80 was phased out by Vaisala in 2005 and replaced by the RS92: at the time of writing, the RS92 radiosonde can only be used in conjunction with a suitable Vaisala ground station, so that new or upgraded ground stations have been needed at almost every preexisting station, at a cost of over $\$ 200,000$ for the entire "AMMA" network. Although the RS92 represents the current state-of-the-art system (Nash et al. 2006), the reliance on a monopoly supplier makes the operator vulnerable to commercial pressure. Therefore, in common with meteorological services worldwide, the African partner agencies in AMMA introduced commercial competition into their network. After a process of tendering, the two new stations at Cotonou and Parakou were installed with ground stations manufactured by the French company Modem. ${ }^{3}$ Ultimately, the deployment of five different radiosonde types ${ }^{4}$ for AMMA has led to significant problems in the use of the measurements, due to the need to calibrate the data (notably

\footnotetext{
${ }^{3}$ At the same time, ASECNA upgraded four of its other stations, including that of Libreville, outside the AMMA network, with Modem systems.

${ }^{4}$ Vaisala RS80 and RS92, Modem, VIZ (at Sal), and GRAW (at the temporary Dano research site).
} 
the humidity; Bock et al. 2007). However, a decision was made that the desired density of soundings could not be achieved within the available budget without some diversity of sonde types to keep the prices down.

Suitable buildings are needed for long-term radiosoundings in West Africa: these amount to a space for gas generation and balloon filling and suitable office space for the ground station and staff (e.g., Fig. 3a). Power, water supply (for gas generation), and space for antennae must all be available, and a phone line is desirable. For AMMA, two new buildings were constructed, for the stations at Tamale and Abuja. In each case the buildings were constructed using architectural drawings provided by ASECNA - one of many examples of international cooperation initiated in AMMA. Surface measurements are also needed as part of the WMOcoded TEMP message-often in Africa these are obtained from a nearby synoptic station, but the instrumentation is not always in good repair.

A range of balloon weights are available. Although $600 \mathrm{~g}$ balloons are regarded as being standard, 350-g balloons were used at most AMMA stations to save costs and reduce gas consumption. Ascent rates are unaffected by the balloon weight, but a heavier balloon will ascend higher: bursting altitudes of the $350-\mathrm{g}$ balloons were typically above $24 \mathrm{~km}$ (around $30 \mathrm{hPa}$ ). In West Africa, balloons are generally filled with hydrogen, which is generated at the station (see the "Gas generation in West Africa" sidebar for details of the methods in use). Parachutes are not generally used on radiosondes over West Africa.

A radiosonde station cannot operate without well-trained and well-motivated staff. With more than 21 active stations (Table 2), there were over 200 radiosonde operators and technicians working on the network during AMMA, and the overall success of the program is a testament to their abilities. At the same time, the body of expertise needs constant renewal, both to replace retired staff and to respond to the development of new technology. There is

sometimes a mentality that African scientists and technicians need to "be trained," implying a passive process in which staff are sent on a 2 -week course and will then be fully capable of all required activities. Of course, training means more than this. It requires a balance between formal teaching and the development of more intuitive experience, generally over longer periods of time, and particularly with access to a tutor or mentor. The area of staff training is one area in which ASECNA enjoys real advantages, through its economies of scale: by combining the income due to meteorological activities in several countries, ASECNA can afford to operate a meteorological training school at Niamey (EAMAC), as well as a meteorological laboratory at its headquarters in Dakar. Together these institutions provide long-term skills and capacity in experimentation, training, and 
The majority of stations fill balloons with hydrogen, generated locally through chemical means, which involves relatively low equipment costs but expensive consumables (see Table 3). Chemical gas generation is a messy, unpleasant, and difficult process. The operator needs to put the chemical charges into the cylinder and then screw on the cylinder head, while pressure is building inside (Fig. 3b). New gas cylinders, with an experienced technician, can fill two 350-g balloons, or perhaps ten $40-\mathrm{g}$ pibal balloons from a single charge, ${ }^{\mathrm{SBI}}$ but this can be far lower with old or damaged cylinders or an inexperienced operator. To perform the high-frequency soundings in 2006 , certain stations required additional cylinders: at Abuja, these were brought in temporarily from neighboring stations in Nigeria.

The chemical ingredients for hydrogen production are shipped from Europe and transported overland from the port of entry, typically crossing one or more national boundaries in Africa. Transportation along these routes takes several months and, if shortfalls are not anticipated, can lead to inter- ruptions to the soundings for several weeks.

At some stations electrolytic methods are used to generate hydrogen. Such methods have low running costs but require an expensive generator and are reliant on costly maintenance in the event of breakdown. Also, electrolytic methods produce oxygen and hydrogen together, and may potentially be more dangerous than chemical means. It should be recognized that there are some physical dangers associated with the use of hydrogen for balloon filling, the fatal accident at the Abidjan station in 2001 being a tragic example.

The Algerian station of Tamanrasset is the only site on the AMMA network to use helium to fill balloons operationally, the gas being purchased in cylinders, as it is in Europe and the United States. A reduced purity of gas is acceptable for balloon filling (sold as "balloon gas"). It is ironic that the cost of balloon gas in Europe, per balloon, is cheaper than the chemicals needed to generate the necessary hydrogen in Africa. However, low purity helium is not available in most West African countries.
SBI The gas requirement is not a linear function of the balloon weight.

\section{STATIONS AND THEIR}

DATA. The operation of a radiosonde station, or of a network of stations, requires effective management to be in place. For instance, to operate a well-founded station, it is necessary to monitor the use of consumables, and to plan future use so that orders can be made well in advance. Another critical aspect of management is the need for responsiveness to technical or operational problems. Failures of hardware are common, and during AMMA there were a number of examples of equipment damage through power surges, or as a result of lightning. Small failures can render a station inoperative until the problem is fixed, which may necessitate the shipping of spares from Europe and arranging for a technician to visit the station. Even relatively lowcost items like a cable may be beyond the budget of the repairs. With financial budgets always being tight, such capacity is difficult to sustain in West African countries outside the ASECNA group.

Operational training of staff at the new stations was conducted by the suppliers of the equipment, Vaisala and Modem. A proposal to use VCP funding to provide this training was not realized, because VCP resources cannot be spent in competition with a commercial organization. This loss was disappointing for several reasons: NMS-led training would have involved "meteorological" content, designed to improve the quality and relevance of the measurements to forecasters, and would have initiated a direct relationship between European NMSs and African meteorological agencies, which could have helped to solve problems in future years. For these reasons, we recommend that future installation and training activities be coordinated through WMO, and that the issue of commercial competition with the instrument supplier be resolved at a high level. local station (or unavailable in the local town). More expensive items involve the additional delays associated with tendering and purchasing. In this area of responsiveness ASECNA suffers problems of internal communications and decision-making, which are a result of its large, distributed structure.

For the most intensive phase of AMMA, in 2006, the ECMWF established a system of regular monitoring of data reception on the GTS. Automatic alarms were activated, in the form of an e-mail message, whenever patterns of reporting suggested a systematic failure in a single station, or in a large group of stations, which in the latter case would imply widespread communication failure. These alarms made it possible to identify problems rapidly.

The management of the AMMA radiosonde program was far from perfect but had the great advantage that it involved all the relevant participants directly, including data collectors, communications agencies, meteorological and NWP centers, members 
of the local GCOS committee, and AMMA research scientists. In many instances, this made it possible to respond to unforeseen problems more effectively than the local operational services alone. Through monitoring of data receipt, problems were identified quickly. Furthermore, some contingency funds were available and could be moved quickly to put a solution into place.

Through the deep involvement of ASECNA in the program, with ASECNA's considerable capacity in skills and training, solutions to many problems could be carried out without intervention from outside Africa, thereby building local capacity. For instance there were many examples of visits of staff between ASECNA and non-ASECNA agencies to solve technical problems or to share in training exercises. Bulk ordering of consumables was carried out by ASECNA, on behalf of several funded science programs in AMMA, and several operational centers in Africa (including the non-ASECNA countries of Algeria, Ghana, Guinea, and Nigeria), leading to considerable savings in the prices.

AMMA has been atypical for a research program, in that the primary radiosonde budget (from AMMAEU) was held by ASECNA, an operational agency, while strategic decisions regarding the deployment of this budget were being driven by scientists in academic institutions. Despite the good spirit of cooperation, which existed in TT1, this imbalance between strategy and executive control led to some delays in the activation of stations in 2006. However, the long-term benefits of the way AMMA has worked have, throughout 2007 , been realized. The fact that the responsibility for budget and implementation has been held in Africa has meant that in 2007 there has been an extremely high success rate in the radiosonde network, including the reactivation of Tessalit (Mali), with most of the impetus for this work coming from the African groups.

COMMUNICATIONS. The existing GTS connections in West Africa are complex and unreliable. In the opinion of the authors of this article, the system has been failing in Africa for more than three decades. Today, there are several means of transmitting meteorological data from Africa, five of which are described below-all have problems of some kind and have been tried in AMMA.

The TEMP message is a relatively short stream of data, containing wind and thermodynamic data at significant and standard levels, which needs to be transmitted into the GTS within an hour or so of the data collection if it is to be useful for NWP. A basic problem with the GTS connection at many stations has been the separation between the radiosonde ground station and the local GTS link, which is often in another building. In such cases, observers have needed to carry the TEMP message by hand to the GTS connection, and there type it manually into the system-clearly this can lead to delays and human errors. AMMA has been able to rectify this situation at several stations through the provision of a direct cable link or a radiolink between the observing station and the GTS link.

From the local GTS point, data are transmitted to a hub (the RTH) and from there into the MTN. The reliance of the system on point-to-point connections leads to considerable vulnerability to single-point failures. In January 2006, at the height of the AMMA dry season operations (SOP0), a failure of the connection between the Dakar RTH and Toulouse led to most of the upper-air data from West Africa for a period of 15 days, with a value in consumables of over $\$ 100,000$ being lost to the GTS. Such failures are depressingly common.

As an alternative to the surface GTS links, satellite communications were used at some AMMA sites. The DCP is a dedicated system for transmitting messages into the GTS through the geostationary meteorological satellites (for Africa, this is Meteosat). A DCP is relatively inexpensive to buy and essentially free to operate, but the system has for some years been unpopular for various reasons. First, data are transmitted to the GTS from a remote station without going through the local meteorological service, meaning that local forecasters do not have direct use of the data and local operators may not immediately get feedback on problems. Second, the DCP is a dedicated system and therefore relies on the operator to deal with maintenance costs. The DCP option was employed for AMMA in parallel with Internet transmission at four sites where the GTS has not worked for many years: Tamale, Parakou, Abuja, and Ngaoundere. ${ }^{5}$ In contrast to the DCP, a VSAT system is a dedicated satellite connection through a commercial provider. At the time of planning for AMMA, new VSAT connections were beyond the budget of the program. However, VSAT data transmission is already used very effectively at some West African stations (e.g.,

\footnotetext{
${ }^{5}$ Use of the DCPs has exposed further mysteries of the GTS. Since the summer of 2006, NCEP has rarely received Parakou, Abuja, and Tamale TEMP messages by GTS, but has often received them from the U.S. Air Force, which intercepts the DCP channel of Meteosat and forwards the data to the U.S. National Meteorological Agency.
} 
Tombouctou), generally in conjunction with the local aviation communications.

Yet another means of getting TEMP messages on to the GTS is to send them via Internet e-mail to operational centers. However, Internet also requires a reliable phone connection, which is not always available at a station. We wish to acknowledge the efforts of those operational staff in Africa who traveled each day to the local cyber café to transmit their data, in some cases a journey of several kilometers on poor roads.

Even where Internet connection is made, the story is still not simple. During AMMA, the four "DCP stations" made provision to send data by e-mail to the ECMWF, who agreed to receive these data and forward them to the AMMA database. However, ECMWF does not have the capacity to submit data to the GTS, so the Met Office kindly agreed also to receive the messages and to perform this function. Unfortunately, ECMWF and the Met Office require different message formats for the e-mails. Given the problems that always arise in ensuring that message formats are precisely followed, this more than doubled the efforts needed to coordinate the transmission of data. We wish to make a strong recommendation for operational centers to agree on a common format for e-mail transmission of meteorological data.

Prior to AMMA, data which failed to reach the GTS would be held at the station, in hard copy or on floppy disk, and there are currently large volumes of such files stored in cupboards across Africa. It is widely regarded to be desirable to "rescue" such data before they decay, but the task is a challenging one. For scientific use, it is also highly desirable to collect the high-frequency $(\sim 1 \mathrm{~s})$ radiosonde data rather than the low vertical resolution TEMP message, which can be retrieved from the GTS. For the AMMA stations, these data are being written to compact disk and sent by post to ASECNA headquarters in Dakar, from where they can be transmitted to the AMMA database.

All methods of transmission of data to the GTS require TEMP messages to be submitted in a precise format, and any small error, typically a single erroneous character in the message, will cause it to be lost. Typically this occurs when the message, sent from a station, reaches an RTH, so that a message with a formatting error never leaves Africa. Failure to correct errors in message formats, before and during AMMA, has led to the loss of radiosonde data from the GTS worth, in consumables, hundreds of thousands of dollars in West Africa alone. A lack of dialogue between the agencies making measurements and the routing hubs, exacerbated by the language barrier between francophone and anglophone nations, has aggravated this already difficult situation (GCOS 2003b).

Even without format errors, routing of messages from a new station, or from an established station making reports outside its normal schedule, requires a significant, coordinated effort. It is necessary to monitor the progress of a series of messages, over a period of a few days, as they leave the station and pass their way through the GTS to one of the NWP centers in Europe or the United States. Therefore, this process involves regular interaction, several times a day, between different organizations in Africa and overseas and needs the availability of a suitable means of communication; e-mail, phone, or fax.

As a final comment on the primary importance of communications in the African meteorological network, we have estimated that the combined value of all soundings, which were made but not communicated to the GTS from the AMMA stations in 2006, in consumables alone, is around $\$ 1.5$ million (some 5,500 soundings; AMMA-EU 2007).

\section{THE AMMA RADIOSOUNDINGS AND} THEIR IMPACT. Some 13,800 soundings were made on the AMMA network in 2006, around half of which were the "operational" soundings. Therefore, the largest single contribution in the funding of consumables for the AMMA radiosonde program came from African partners. Figure 4 summarizes the reception statistics for tropospheric radiosonde data at the ECMWF, for the 21 primary AMMA stations. The overall success rate for 2006, as measured by data reception on the GTS relative to our plans, was $54 \%$. This rate was lower than has been achieved in pre-AMMA years, partly because of the increased frequencies of soundings failing to match the planned increases in March and April 2006 , and partly because of a severe GTS failure in January of that year. Of the $46 \%$ of soundings missing from the GTS, we have estimated that $34 \%$ were due to failure of communications (AMMA-EU 2007). Prior to AMMA, such missing data were stored on floppy disks or paper records, each of which can decay over a few years, and these data have not been available for scientific use without a special effort of collection. From the AMMA period, most of the missing data are now being collected a posteriori for the project database. Around $12 \%$ of planned soundings were not made, because of technical problems or failures of supply.

Due to continuing work on the infrastructure and communications, in the first 6 months of 2007 the success rate on the GTS across the 21 AMMA 
stations increased to $79 \%$, while in August 2007 the success rate peaked at over $88 \%$ for the month. More significantly, from the whole EOP we have found that stations which have good infrastructure and are supplied with consumables can achieve $95 \%$ success or better (Table 2). This confirms that the primary problems of the network are the supply of consumables and communications.

During two periods of the AMMA SOPs in the summer of 2006, eight per day soundings were made at six stations in the network, comprising the quadrilateral of Cotonou, Tamale, Parakou, Abuja, and Niamey, along with Agadez as a reliable northern station (Fig. 1). The intensive sounding periods were denoted IOP5.1 (20-29 June 2006) and IOP5.2 (1-15 August 2006). Although high-frequency measurements of this kind have been made in several field experiments around the world, we are not aware of such 3-hourly observations being made with locally generated hydrogen, even for shorter periods of time. The dedicated efforts of the staff at the stations involved meant that $98 \%$ of soundings were successfully made. Transmission of the data was less successful, with some stations experiencing sustained problems for one or both of the IOPs.

Part of the problem in maintaining the upper-air network over Africa has come from a lack of clear understanding of the value of these data to weather prediction and climatic analysis. In attempting to evaluate the impact of radiosonde data on operational analyses, Tompkins et al. (2005) argued that

\footnotetext{
Given the limited resources of many of the African nations, it is not pragmatic simply to recommend increased resolution and frequency of upper-air observations.... it is first necessary to establish the importance of different data streams within the current observing system to practical NWP and climate prediction.
}

Similarly, unless the real-time access to and usefulness of NWP products can be demonstrated to forecast offices in Africa, there will remain little direct motivation for local agencies to transmit their measurements for assimilation.
Analyzing one week in 2000, Tompkins et al. (2005) found that radiosonde data are the most important data stream in generating high-quality numerical model analyses for the study period. In a more detailed case study investigating mesoscale convective systems in the vicinity of an experimental radiosonde station at Parakou in 2002, Schrage et al. (2006) provide evidence that even the presence of this single upper-air station in the Soudanian zone of West Africa had a beneficial impact on the lowlevel wind, temperature, and moisture fields in the ECMWF operational analysis. The AMMA radiosonde program, through presenting a radiosonde dataset that has good regional coverage for two monsoon seasons, and possibly longer, will allow us to perform much more systematic studies of the value of radiosonde and other data. A typical approach to this will be to perform OSEs in which model analyses and forecasts are regenerated with and without the assimilation of certain sets of data. These kinds of studies are being coordinated through a joint working group with the THORPEX program (AMMA WG5) and will involve an ECMWF reanalysis for 2006, making use of data from the many soundings that were made but not transmitted, and therefore not assimilated operationally. 
REFLECTION AND RECOMMENDATIONS.

It is generally agreed that the monitoring and prediction of weather and climate for Africa are of utmost importance to the local populations and to the global community. Through AMMA, we have learned many lessons about the current state of operational monitoring of the atmosphere and about the issues involved in putting improvements in place.

In recent months we have been asked the question of how AMMA succeeded to invigorate the West African radiosonde network, in the face of decades of decline and a pessimistic operational community. A superficial answer to this would simply be that we commanded a research budget of some $\$ 3.5$ million. However, much of this budget was spent on upgrades required by the replacement of the RS 80 sonde, and on additional soundings required for scientific purposes in 2006, so the level of funding cannot entirely explain the robust state of operations at the time of writing. Furthermore, previous projects in Africa will confirm that high spending does not guarantee a successful outcome. Our own judgement is that the success of the AMMA radiosonde program can be attributed to active management and cooperation among the diverse partners in AMMA, the strong involvement of the African agencies in the management of the core budget, and the availability of (relatively small) contingency funds for rapid response to failures.

Today, the radiosonde network in West Africa looks healthy, but it is difficult to predict how this will evolve in the coming years. There are some deep problems in African meteorological operations, at the root of which is the lack of financial resources in many individual countries, and the meteorological community on its own cannot solve these problems. However, many issues such as the establishment of useful communications should be within our capacity. From our experiences over the last 3 years we wish to offer some recommendations:

1) Regional management of the observing network is needed. This coordination needs genuine power to solve problems, in the form of financial, human, and decision-making resources in the agencies concerned, which was not the case for the GUAN station at Abidjan in recent years. Management and maintenance need financial support and infrastructure: for instance, resources such as VCP should be better integrated with a regional strategy.

2) Training of staff in Africa needs to involve longterm cooperation with the European and U.S. partners, and should be part of a regional strategy, rather than being piecemeal. Increased cooperation within Africa is needed to build on the critical mass which ASECNA, for example, holds.

3) Data transmission is in a poor state and needs to be sorted out. The value of soundings that have not been assimilated greatly exceeds the costs required to repair the communications. We need to agree on a common format for e-mail TEMPs, to upgrade links between GTS hubs, to find and prioritize funds to connect "silent" stations to the GTS (e.g., Sarh), and to implement "backup" transmission systems.

For the future, we hope that the science being pursued by AMMA-THORPEX will provide guidance and priorities for operational strategy. Right now, evidence indicates that radiosondes over Africa are very important for the generation of good weather prediction and consistent climatic monitoring. Beyond this, we need a long-term strategy for a sustainable network, motivated by evaluation of the data impacts involving the needs of the African agencies, and taking into account the use of the data and the way in which the products of the data are relayed back to the NMS.

For some years, many parts of the international community have felt that the radiosonde network over Africa is in terminal decline, and will ultimately be replaced by systems controlled by the "northern" countries of the world; systems such as AMDARS and satellite sensors. We regard this to be a dangerous route for the global and African observational network to follow. Currently, there is no technology that can provide the density, accuracy, and vertical resolution of lower-tropospheric wind and thermodynamic data offered by the radiosondes, and therefore the network remains very important. During AMMA we have confronted the many problems faced by the upper-air network in the region, and made considerable progress in establishing a robust network at the current time. This network will only have a sustainable future if it is supported intelligently.

ACKNOWLEDGMENTS. With more than 200 people actively involved in the AMMA radiosonde program, it is unfortunately not possible to name all of them here, but we would like to acknowledge their very great collective effort.

Brad Ballish, Janvier Bentefouet, Olivier Bock, Wil Doran, Howard Diamond, Philippe Drobinski, Ali El Majdoub, Tuija Eriksson, Peter Eriksson, Cyrille Flamant, Antonio Garcia-Mendes, Karine Ginoux, Marielle Gosset, Mohamad Kadi, Norbert Kalthoff, 
Peter Lamb, Mathieu Nuret, Jamie Palmer, Steve Palmer, Christophe Peugeot, and Richard Smout have all made considerable contributions to the management of the program and its international connections. We are also grateful to students and staff from the University of Cologne who managed the European contribution to the implementation of new radiosonde stations at Abuja and Tamale, notably Dr. Michael Christoph and Dipl. Met. Susan Pohle.

Based on a French initiative, AMMA was built by an international scientific group and is currently funded by a large number of agencies, especially from France, the United Kingdom, the United States, and Africa. It has been the beneficiary of a major financial contribution from the European Community's Sixth Framework Research Programme (AMMA-EU). Detailed information on scientific coordination and funding is available on the AMMA international Web site (www.ammainternational.org).

The largest contribution of finances, facilities, and personnel for the AMMA upper-air program and its management came from the operational commitments of the African meteorological agencies. Funding has also been provided by AMMA-EU, the French Program ACI RNCC 2003, NERC (NE/B505538/1), NASA African Monsoon Multidisciplinary Activities (NAMMA), and the ARM program.

\section{REFERENCES}

AMMA-EU, cited 2006: D4.1.1.d: Report on sonde statistics. [Available online at www.amma-eu.org/ workspaces/work_package_s_workspace/toolsmethods/wp4_1/deliverables/d4-1-1d-sondestatistics.]

— , cited 2007: D6.1.e: Report on data submitted to database. [Available online at www.amma-eu.org/ workspaces/work_package_s_workspace/demonstration-training/wp6_1/deliverables/d6-1-e-reporton-data.]

Beck, C., J. Grieser, and B. Rudolf, 2005: A New Monthly Precipitation Climatology for the Global Land Areas for the Period 1951 to 2000. German Weather Service. Climate Status Rep. (Klimastatusbericht) 2004, 181-190. [Available online at www.dwd.de/ de/FundE/Klima/KLIS/prod/KSB/ksb04/28_precipitation.pdf.]

Bock, O., M.-N. Bouin, A. Walpersdorf, J. P. Lafore, S. Janicot, F. Guichard, and A. Agusti-Panareda, 2007: Comparison of ground-based GPS precipitable water vapour to independent observations and NWP model reanalysis over Africa. Quart. J. Roy. Meteor. Soc., 133, 2011-2027.
Carr, M. T., and C. S. Bretherton, 2001: Convective momentum transport over the tropical Pacific: Budget estimates. J. Atmos. Sci., 58, 1673-1693.

GCOS, 2003a: The second report on the adequacy of the global observing systems for climate in support of the UNFCCC. GCOS 82, WMO/TD 1143, 74 pp. [Available online at www.wmo.int/pages/ prog/gcos.]

_ 2003b: Report of the GCOS regional workshop for Western and Central Africa on improving observing systems for climate. GCOS 85, WMO/TD 1167, $88 \mathrm{pp}$. [Available online at www.wmo.int/pages/ prog/gcos/.]

Higgins, W., and Coauthors, 2006: The NAME 2004 field campaign and modeling strategy. Bull. Amer. Meteor. Soc., 87, 79-94.

Johnson, R. H., and P. E. Ciesielski, 2000: Rainfall and radiative heating rates from TOGA COARE atmospheric budgets. J. Atmos. Sci., 57, 1497-1514.

Kuettner, J. P., and D. E. Parker, 1976: GATE: Report on the field phase. Bull. Amer. Meteor. Soc., 57, 11-27.

Nash, J., R. Smout, T. Oakley, B. Pathack, and S. Kurnosenko, cited 2006: WMO intercomparison of high quality radiosonde systems. [Available online at www.wmo.int/pages/prog/www/IMOP/intercomparisons.html.]

Parker, D. J., and Coauthors, 2005: The diurnal cycle of the west African monsoon circulation. Quart. J. Roy. Meteor. Soc., 131, 2839-2860.

Redelsperger, J.-L., C. D. Thorncroft, A. Diedhiou, T. Lebel, D. J. Parker, and J. Polcher, 2006: African Monsoon Multidisciplinary Analysis: An international research project and field campaign. Bull. Amer. Meteor. Soc., 87, 1739-1746.

Schrage, J. M., A. H. Fink, V. Ermert, and E. D. Ahlonsou, 2006: Three MCS cases occurring in different synoptic environments in the sub-Sahelian wet zone during the 2002 West African monsoon. J. Atmos. Sci., 63, 2369-2382.

Tompkins, A. M., A. Diongue-Niang, D. J. Parker, and C. D. Thorncroft, 2005: The African easterly jet in the ECMWF Integrated Forecast System: 4D-Var analysis. Quart. J. Roy. Meteor. Soc., 131, 2861-2886.

Vera, C., and Coauthors, 2006: The South American Low-Level Jet Experiment. Bull. Amer. Meteor. Soc., 87, 63-77.

WMO, cited 2006: Observing stations and WMO catalogue of radiosondes. WMO Publication No. 9, Vol. A. [Available online at www.wmo.ch/pages/prog/ www/ois/volume-a/vola-home.htm.] 


\section{Meteqralggical Manggraph Na. 50}

Edited by Charles Doswell III

\section{Severe Convective Storms} Charles A. Doswell III, Editor

American Meteorological Society
This volume is a collection of 13 review papers by a distinguished group of scientists, providing a summary of the current scientific understanding of convective storms and the weather they produce, as well as showing how that understanding works in forecasting practice. The volume is loaded with outstanding illustrations, and is destined to become one of the most widely referred-to books on convection and convective processes.

\section{SEVERE CONVECTIUE STORMS, Meteorological Monograph No. 50}

ISBN 1-878220-41-1, 576 pp., hardbound, \$110 list/\$90 member, student member price: \$75. To place an order, submit your prepaid orders to Order Department, AMS, 45 Beacon Street, Boston, MA 02108-3693; call 617-227-2425 to order by phone using Visa, Mastercard, or American Express; or send e-mail to amsorder@ametsoc.org. Please make checks payable to the American Meteorological Society. 